\title{
La promoción de la inmigración de trabajadores agrícolas asiáticos a Yucatán (1880-1910).
}

Fernando Saúl Alanís Enciso

EL COLEGIO DE SAN LUIS POTOSÍ

\begin{abstract}
En este artículo se analizan los argumentos que determinaron el ingreso de trabajadores agrícolas asiáticos a la industria henequenera de Yucatán durante el porfiriato.
\end{abstract}

$\mathrm{D}$ urante el porfiriato algunos funcionarios y empresarios henequeneros yucatecos afirmaban que no había mano de obra suficiente para el desarrollo de sus empresas. Con base en este argumento, de escasez, tanto de mano de obra como de población en general en la región, promovieron medidas para impulsar el ingreso de trabajadores extranjeros. La iniciativa local encontró eco en los altos círculos del gobierno mexicano, entre otras razones por el proyecto de nación que éste deseaba construir y el tipo de industrias que estaba apoyando.
Los ideólogos porfiristas consideraron que los indios, que conformaban la mayor parte de la población, no eran adecuados para el despegue industrial y agrícola que requería el país. Eran bárbaros que vivían al margen de la cultura nacional, incapaces de tareas industriales y de los cuales no podía esperarse "nada, enteramente nada". ${ }^{1}$ En busca de una solución, en el marco ideológico y económico del grupo gobernante de la época, se propuso que la mano de obra fuera traída 68.

'González Navarro, Extranjeros, vol. II, p.

núm. 37, enero-abrit 1997 
del exterior, de Europa principalmente. Con ese fin se promovió su ingreso, sin embargo fueron pocos los que llegaron de ese continente. Asimismo, a pesar de la antipatía a los asiáticos y sobre todo a los chinos, éstos empezaron a llegar, pues fueron considerados peones de calidad, baratos, resisten. tes y dóciles. Una parte de ellos arribó a Yucatán a trabajar en las plantaciones de henequén.

El objetivo de este trabajo es reflexionar sobre las razones por las cuales los empresarios henequeneros yucatecos promovieron el ingreso de trabajadores agrícolas asiáticos y en particular analizar los argumentos de los promotores de esta inmigración. La propuesta de este ensayo es que el razonamiento de los grandes productores henequeneros sobre la falta de mano de obra, no fue verdadera. El propósito es demostrarque en Yucatán existía la fuerza de trabajo suficiente para cubrir las necesidades de los productores. Sin embargo, había un alto porcentaje de población indígena no sojuzgada que era renuente a participar en el régimen de trabajo henequenero. Esta situación originó una percepción y un discurso que suponían falta de brazos, lo cual propició el ingreso de mano de obra extranjera.

Para demostrar mi proposición he dividido el estudio en cuatro partes. En la primera presento un breve resumen del desarrollo de la industria henequenera a partir del siglo XIX. En la segunda estudio a los promotores de la inmigración, así como sus razones para impulsar la entrada de extranjeros, y analizo la política del gobierno mexicano en apoyo a tales iniciati- vas. En la tercera examino las cifras de asiáticos que estuvieron en Yucatán trabajando en el henequén, su representatividad e importancia cuantitativa en el contexto de la mano de obra que era empleada en las plantaciones de la región. Analizo los datos referentes a la población yucateca y la cantidad de mano de obra que estaba disponible en las plantaciones, así como el sistema de trabajo imperante. Asimismo, llevo a cabo una interpretación acerca de las razones que motivaron a los grandes cultivadores a promover el ingreso de inmigrantes.

\section{EL HENEQUÉN EN YUCATÁN}

La inmigración asiática a Yucatán estuvo determinada por muchos factores. El principal fue el gran desarrollo de la industria henequenera. Durante la segunda mitad del siglo XIX, comenzó a cobrar importancia el cultivo del henequén en Yucatán. En un principio el desarrollo yucateco, impulsado por inversionistas de la región, tuvo una diferencia significativa con la manera en que operaban otros en el resto del país. En la península ellos controlaban las plantaciones, los ferrocarriles, etc. Además, desarrollaron un régimen que abarcaba a los capitalistas, los concesionarios, los ingenieros y los trabajadores. $^{2}$

Para la explotación en gran escala se impulsó la mecanización de la pro. ducción que se hacía manualmente. El propio gobierno convocó a varios

${ }^{2}$ Monsely y Terry, Yucatan, p. 208. 
concursos para la invención de máquinas para la explotación. Mientras tanto, en Estados Unidos se inventó la máquina cosechadora y engavilladora de trigo (Mac Cormick). El inventor llevó a cabo numerosas pruebas con distintas clases de fibras vegetales para fabricar un cordel que pudiera sustituir al alambre en las máquinas engavilladoras. La más adecuada para ello era la fibra del henequén. ${ }^{3}$

El periodo de la prosperidad del henequén yucateco coincidió con el gobierno de Porfirio Díaz, quien promovió el desarrollo de nuevas industrias de exportación con base en la apertura de puertos y la construcción de ferrocarriles ligados al capital extranjero. ${ }^{4}$ En tanto, la difusión mun. dial de la engavilladora produjo una demanda de la fibra, misma que en aquel tiempo sólo podía obtenerse en Yucatán. Sin embargo, las plantaciones requerían largos años de cultivo y la inversión de cuantiosos capitales. ${ }^{5}$ Fue así como los grandes agricultores yucatecos buscaron fuera del país los capitales necesarios para sembrar y cultivar sus plantíos.

En Yucatán había varias casas comerciales que, como agentes de las estadunidenses o por cuenta propia, se dedicaban a la compra y exportación de la fibra de henequén. Las principales eran la E. Escalante Bates y $M$. Dondé, que operaban en conexión con la firma de Thebaud Brothers de Nueva York, quien les abrió amplios

${ }^{3}$ Molina, Tragedia, pp. 59-61; Monsely y Terry, Yucatan, p. 208.

${ }^{4}$ Monsely y Terry, ibid.

5 Molina, Tragedia, p. 61. créditos. ${ }^{6}$ En 1895 se fundó la casa de O. Molina y Compañía, que operó en conexión con G. Amsinck Compañía de Nueva York. Al iniciar el siglo XX, se formó la International Harvester Corporation, que desde entonces fue el principal consumidor de fibra yucateca. ${ }^{7}$ La actividad henequenera en gran escala nació del financiamiento estadunidense y del mercado internacional, particularmente de Estados Unidos.

$\mathrm{El}$ auge del henequén como actividad comercial trajo transformaciones económicas, sociales y políticas en el estado de Yucatán. De acuerdo con Moisés González Navarro, en 1883 menos de la cuarta parte de las haciendas de la región, 843 de 4139 , se dedicaban al cultivo del henequén. La totalidad de los partidos en Mérida y $\mathrm{Hu}$. nucmá, dos terceras partes de los de Progreso, una tercera parte de los de Acanceh, 'Tixkokob, Maxcanú, Motul, etc. ${ }^{8}$ Esto cambió la economía de la hacienda yucateca, basada en el maíz y la ganadería, a una agricultura de monocultivo de henequén con objetivos comerciales para el mercado mundial. Fredrich Katz afirma que al terminar el siglo XIX y comenzar el XX, con el enorme incremento de la producción henequenera, el cultivo del maíz descendió de 15000 hectáreas en 1894 a 4500 en 1907.9

La expansión de la producción henequenera también tuvo como con-

${ }^{6}$ Ibid., p. 75. 147.

7 Ibid., p. 77; Monsely y Terry, Yucatan, p.

${ }^{8}$ Villanueva, Tomamos, p. 80; González Navarro, Raza, p. 185.

${ }^{9}$ Katz, Servidumbre, p. 28. 


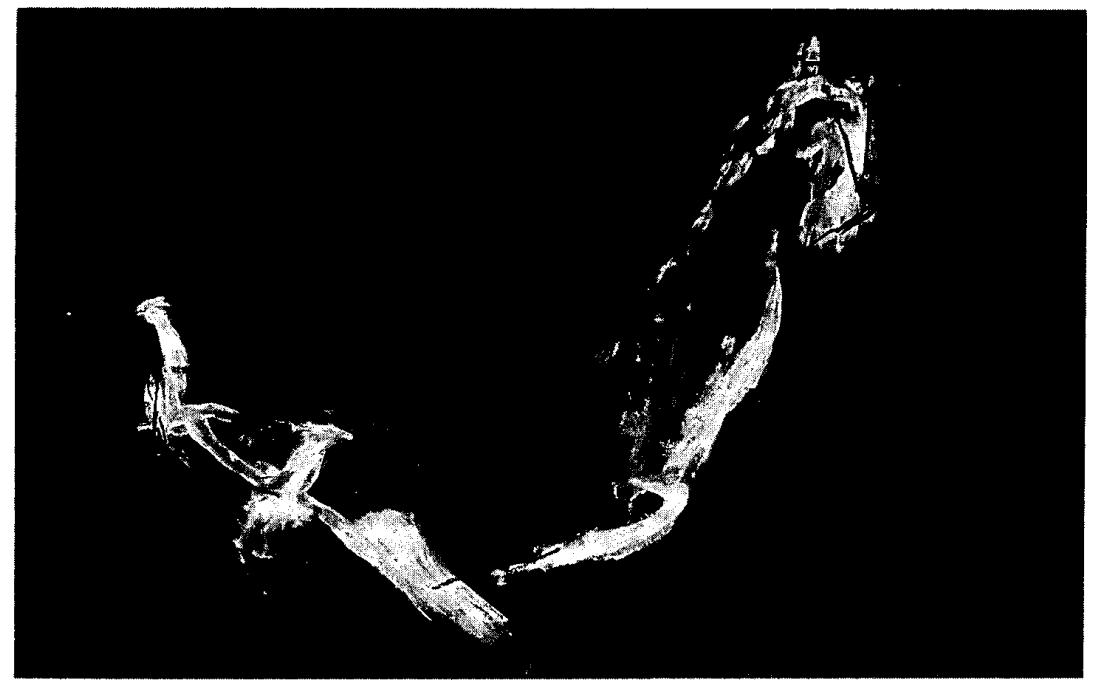

secuencia un incremento notable en la demanda de mano de obra. En este contexto, un grupo de empresarios promovió el ingreso de inmigrantes agrícolas asiáticos y de otras nacionalidades. ¿Quiénes apoyaron ese interés en importar mano de obra y cuáles fueron sus argumentos para justificar su ingreso al país?

LOS PROMOTORES DE LA INMIGRACIÓN ASIÁTICA

Durante el porfiriato la inmigración de trabajadores extranjeros a Yucatán no fue una novedad. En algún tiempo había sido de cubanos, canarios y puertorriqueños. Sin embargo, en 1891 algunos hacendados yucatecos pensa- ron en contratar jornaleros chinos, entre los cuales se encontraban los que ya trabajaban en las obras del ferroca. rril de Tehuantepec. A otros se les mandaría traer directamente de la colonia inglesa de Hong Kong, para atender el cultivo de las plantaciones henequeneras. Según ellos, se trataba de solventar la crisis de mano de obra disponible, que se había agravado por la deserción de los jornaleros indígenas. ${ }^{10}$

Pedro de Rengil Peón, Manuel Dondé y José García, importantes empresarios henequeneros, informaron a la Secretaría de Hacienda que en Yucatán no existía problema de trabajo porque abundaban las tierras y había libertad

${ }^{10}$ Gómez,Movimiento, pp. 49-50; González Navarro, Extranjeros, vol. II, p. 288. 
de empleo, pero escaseaban los trabajadores. ${ }^{11}$ Es decir, los promotores de esta propuesta fueron principalmente hacendados henequeneros. Su argumento fue la falta de mano de obra. Este grupo no estaba solo ya que contaba con el apoyo de otros empresarios.

En una reunión de hacendados, comerciantes y hombres de negocios yucatecos realizada en noviembre de 1891 para tratar acerca de la contratación de chinos, el secretario de esa reunión, Serapio Rendón, lamentaba la ruina de los propietarios, que atribuía a la escasez de trabajadores. ${ }^{12} \mathrm{De}$ bido a esto, en la misma reunión se decidió importar los jornaleros necesarios de China. Acordaron con Hiloy y Compañía de Hong Kong y de San Francisco, California, un enganche inicial de 484 chinos procedentes de Tehuantepec y de Hong Kong. En el contrato se estableció que los primeros vendrían por año y medio y los otros por tres años. ${ }^{13}$

El economista mexicano defendía, desde una óptica positivista-científi$\mathrm{ca}$, los intereses de los hacendados y en general de los empresarios. Sostenía que aunque el chino tenía "pasiones de mal género" que lo hacían "antipático y repulsivo ética y estéticamente", era dócil y resistente en su calidad de peón, por lo que manifestó su apoyo "doctrinario" a la resolución de "ensayar" el cultivo de tierras con asiáticos contratados por cierto número de años. ${ }^{14}$

"González Navarro, Raza, p. 200.

12 Gómez, Movimiento, pp. 49-50.

13 Ibid., p. 50.

${ }^{14}$ Ibid., p. 51.
El interés de los hacendados por disponer de esa mano de obra, no tanto barata sino dócil, se sobrepuso al temory la repulsa que la presencia china en México despertaba en algunos positivistas. De esta manera se apoyó la inmigración de jornaleros chinos, calificados como "los mejores, más resistentes, baratos y fiables", 15 características opuestas a las que servían para calificar a la gran población indígena maya, que en muchos casos no estaba "disponible" por su lucha contra los grupos opuestos a su cultura. Se prefería a los chinos, en general a los asiáticos, explicaba el gobernador de Veracruz en 1904, porque ellos ofrecían las mejores esperanzas de éxito "para el resultado práctico de nuestras experiencias agrícolas" ${ }^{16}$

Desde los años ochenta empezó a promoverse la idea de traer chinos como peones agricolas y jornaleros, no para fundar colonias de inmigrantes, sino en condición de "herramientas", "máquinas de trabajo", o "motores de sangre", como se refirió a ello la prensa positivista. ${ }^{17}$ Con el tiempo se confirmó que la inmigración china, y en general la asiática, sería muy numero. sa, sobre todo después de que Estados Unidos cerró las puertas a esta corriente migratoria con la Ley de Exclusión China de 1882 (Chinese Exclusion Act). Entonces, parte de este flujo empezó a desviarse a México, primero al Pacífico Norte y después se extendió a to-

15 Ibid., p. 52.

16 Pong, Koreans, p. 17; González Navarro, Colonización, pp. 32-33; Raza, p. 212.

17 Puig, Matanza, p. 179; González Navarro, Extranjeros, vol. II, p. 283. 
do el país. ${ }^{18}$ El primer estímulo oficial para promover la inmigración china a México se llevó a cabo en 1899. Después de un largo proceso de negociación oficial se firmó un tratado con China, no solamente para permitir el libre ingreso de los ciudadanos de ambos países, sino para formalizar las relaciones diplomáticas. ${ }^{19}$

Finalmente, a principios del siglo $\mathrm{xx}$, los productores henequeneros idearon el plan para traer inmigrantes asiáticos. El proyecto fue realizado por John G. Meyers, nacido en Holanda y nacionalizado inglés, y representante de los productores de henequén de Yucatán. Fue enviado a Corea a buscar trabajadores, así como a contratar japoneses y chinos. ${ }^{20}$ Para llevar a cabo su proyecto, los agricultores yucatecos requerían además el apoyo gubernamental. En realidad no tuvieron problemas para obtenerlo ya que éste fue su mejor aliado tanto por lo que se refería al apoyo y protección de sus empresas, como por la ideología para impulsar el desarrollo del país.

Durante el gobierno del general Porfirio Díaz los gobernantes estuvieron a favor de una política de inmigración que promoviera el ingreso de trabajadores extranjeros a México. El objetivo, en un principio, fue colonizar. Luego, al fracasar el proyecto, se promovió el ingreso de extranjeros como mano de obra en industrias ligadas al capital extranjero.

${ }^{18}$ González Navarro, Raza, p. 211; Extranjeros, vol. II, p. 68.

19 Pong, Koreans, p. 17.

20 Patterson, Korean, p. 1; Pong, Koreans, p. 25; Romero, "Coreanos", p. 98; Romero, "Haciendas", p. 40.
Población escasa y tierra abundante, fértil y baldía, eran las premisas en que se basaba la necesidad de atraer inmigrantes que pasaran de la potencia al acto, las legendarias riquezas del país. ${ }^{21} \mathrm{Al}$ igual que los henequeneros, los funcionarios mexicanos consideraban que la escasez de mano de obra detenía el desarrollo de los abundantes recursos naturales y estaban de acuerdo en un razonamiento: faltaban trabajadores. Sin brazos los recursos no podrían ser explotados o desarrollados. La entrada libre de inmigrantes sería un elemento para iniciar el desarrollo económico y un requisito para el despegue industrial. Como consecuencia, nuevas leyes fueron sancionadas para alentar la colonización e inmigración a regiones no desarrolladas, entre ellas, Yucatán. ${ }^{22}$

Para los funcionarios porfiristas, México reunía las condiciones para ser un país rico, civilizado y próspero, pero su exigua población, tanto por su número como por sus aptitudes, era el principal factor de los varios que impedian el aprovechamiento de las incalculables y fabulosas riquezas que atesoraba el suelo patrio. Los esfuerzos estaban encaminados a modernizar rápidamente al país. Así, el régimen de Díaz estableció la paz, suprimiendo militarmente las rebeliones internas y abrió las puertas a la inversión extranjera. Llegó el capital y las empresas que México necesitaba para explotar sus recursos naturales. Además, se otorgaron varias concesiones para la cons-

21 González Navarro, Extranjeros, vol. 11, p. 51; Colonización, p. 1.

22 Pong, Koreans, p. 5. 
trucción de ferrocarriles, puertos, telégrafos, instalación de fundidoras de metales, etcétera. ${ }^{23}$

Los contenidos de la política de inmigración consideraban que los indígenas eran la parte bárbara, no desarrollada de la sociedad mexicana y que estaba al margen de la cultura nacional. Entre ellos los mayas, los tarascos, los zapotecas, los mixtecos, los yaquis, etc., no podían considerarse como trabajadores disponibles para llevar a cabo grandes empresas, sobre todo porque en algunos casos ni siquiera se había logrado pacificarlos y eran vistos como un obstáculo para el desarrollo económico del país. La conformación racial y cultural de la república mexicana se convirtió en tema de discusión paralelo al de la política de inmigración. ${ }^{24}$ Sin embargo, los proyectos en general fallaron y fueron pocos los extranjeros que llegaron al país.

Los argumentos de falta de mano de obra parecían una realidad a los ojos de los grandes productores agrícolas y de los funcionarios gubernamentales. Más aún, estos grupos estaban convencidos de que en realidad era un factor que frenaba el desarrollo del país, y que de no resolverse llevaría a la ruina a sus empresas. Calculando que la solución eran los inmigrantes, en este caso los asiáticos, apoyaron el ingreso. Pero ¿cuál fue su importancia cuantitativa? ¿Llegaron a tener una representatividad importante en la mano de obra de la producción henequenera yucateca?

23 Ibid., p. 7.

${ }^{24}$ Ibid.
¿CUÁNTOS LLEGARON?: ANÁLISIS CUANTTTATIVO DE LA INMIGRACIÓN ASLÁtica A YUCATÁN

En general, la inmigración asiática que llegó a Yucatán a trabajar en las plantaciones de henequén fue poca. Estuvo compuesta por chinos, coreanos y un pequeño grupo de japoneses. La baja inmigración obedeció al sistema de explotación de los trabajadores en las haciendas henequeneras, que llevó a los chinos a desistir de contratarse, previno a los japoneses de hacerlo y sólo los coreanos, ignorantes de estas condiciones, aceptaron la oferta. Asimismo, se frustró la posibilidad de continuar la corriente migratoria debido a la operación fraudulenta del comisionado de los henequeneros yucatecos -Meyers- y las presiones de altos funcionarios del gobierno de Japón que redundaron en la prohibición de toda emigración. ${ }^{25}$

En 1895, la inmigración asiática ascendía a 1433 individuos y aumentó a 20194 en 1910. Los chinos, el grupo más numeroso, creció notablemente en la misma fecha de 897 a 13 203. En Sonora y en Sinaloa vivía la mitad y en 1910 se extendió a otras entidades co. mo Yucatán, Distrito Federal, Chihuahua, Baja California, etc. ${ }^{26}$ Por Salina Cruz entró la mayor cantidad de chinos en la primera década de este siglo. En 1903, 57 llegaron como una avan. zada de 25000 destinados a Yucatán. ${ }^{27}$

Los japoneses, por su parte, llegaron después en un número pequeño

25 Patterson, Korean, pp. 15-31.

${ }^{26}$ González Navarro, Colonización, p. 91.

27 Ibtd., p. 84. 

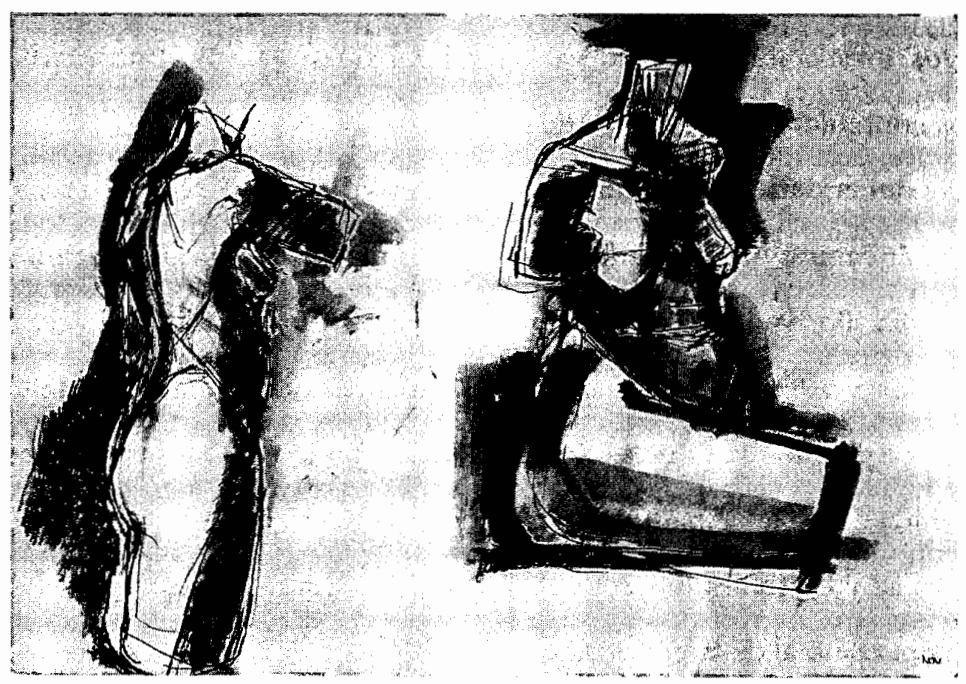

que las investigaciones no han precisado por su escasa representatividad. Por su parte, en marzo de 1905, Meyers, enviado de los henequeneros, ya había reunido en Corea, con ayuda de la Compañía Continental de Colonización-empresa encargada de enviar trabajadores japoneses a Hawai- 1033 inmigrantes, entre los que estaban 702 hombres, 135 mujeres y 196 niños. $^{28}$ Al poco tiempo se corrió el rumor de que los había enviado en calidad de esclavos. Además, un periódico coreano informaba que el gobierno de ese país tenía conocimiento de que sus ciudadanos emigraban a México para ser vendidos y tratados como escla-

${ }^{28}$ Patterson, Korean, p. 3. vos, por lo cual pedía se prohibiera salir a más personas. ${ }^{29}$

Al principiar el siglo xx los henequeneros yucatecos proyectaron la llegada de 500 a 600 familias japonesas, inmigración que no prosperó porque al finalizar el porfiriato el gobierno japonés prohibió la inmigración de sus nacionales a México. Según algunas fuentes los japoneses desistieron de esa idea por las "calumnias" que John Kenneth Turner escribió sobre Yucatán. ${ }^{30}$ Pero si los japoneses emigraron en peque-

${ }^{29}$ Ibid., p. 5; Romero, "Coreanos", p. 98; "Haciendas", p. 41; González Navarro, Extran. jeros, vol. II, p. 286.

${ }^{30}$ González Navarro, Raza, p. 213; Turner, México, p. 34. 
ño número, en 1910 la corriente migratoria coreana fue la mitad de la china.

Uno de los estudios pioneros sobre la inmigración de asiáticos a Yucatán, realizado por González Navarro, considera que en 1905 llegaron 200 coreanos, contratados para trabajar cuatro años. ${ }^{31}$ Un estudio más reciente basado en información diplomática de archivos de Japón, afirma que fueron 1033 coreanos los cuales salieron del puerto de Chemulpo - hoy Inchonhacia México; sólo dos murieron en el trayecto y el resto desembarcó en Salina Cruz (1 031). Sin embargo, sólo llegó a Yucatán alrededor de la cuarta parte. De hecho, el censo de 1910 registró la presencia de 310 coreanos y 875 chinos. ${ }^{32}$ De acuerdo con los datos recabados en Yucatán por los representantes enviados por la Kungminjoe, Asociación Nacional Coreana de los coreanos residentes en Hawai y en Estados Unidos, publicados en su órgano New Korea en su edición de 30 de noviembre de 1910 , se estimaba que la población de coreanos residentes en Yucatán era de 784 personas (613 hombres y 171 mujeres). 33

John K. Turner, que con su célebre México bárbaro conmovió a la opi-

31 González Navarro, Raza, p. 213.

32 González Navarro, Colonización, p. 85; Extranjeros, vol. II, p. 286, ahí el autor afirma que el censo de 1910 registró 306 coreanos en Yucatán. Pong, Koreans; Romero, "Coreanos", pp. 99,101 . En el censo de 1920 se recoge un total de 327 y en el de 1930 se señalan 219. En la década de los veinte 288 de los inmigrantes coreanos salieron de Yucatán con rumbo a $\mathrm{Cu}$ ba, cifra que representa casi el total de los coreanos registrados en el censo de 1910 .

${ }^{33}$ Romero, "Haciendas", pp. 41-42. nión pública de México y Estados Unidos, comentaba que al lado de los 50 reyes del henequén, había 8000 yaquis, 3000 coreanos y entre 100000 y 125000 mayas. ${ }^{34}$ Es decir, los asiáticos representaban aproximadamente $3 \%$, o menos, de la mano de obra que ahí se empleaba, siendo poca su representatividad en el total de los trabajadores de esas plantaciones. ${ }^{35}$ De esta manera, fueron mayores las exageraciones y los proyectos de los henequeneros sobre inmigrantes asiáticos, que la realidad.

Resumiendo cifras puede decirse que en 1903 llegaron 57 chinos y en 1910 había 875. En 1905 llegaron 200 coreanos y en 1910 había 306 . En 1895 había 1433 asiáticos y en 1910 eran 20 194, en su mayoría chinos. A partir de la cifra de 1910, sabemos que había menos de 1000 chinos ese año. Quizá éste fue su número aproximado en los años anteriores. Aun cuando parece elevada la cifra, no representaba ni $1 \%$ de la mano de obra en las fincas yucatecas. Un estudio sobre la inmigración coreana reconoce que el movimiento de los inmigrantes en 1905 fue relativamente insignificante.

De esta manera la mano de obra asiática no llegó a ser importante cuantitativamente en el contexto yucateco. Con base en las cifras expuestas puede decirse que esta inmigración no fue una solución a la. "falta de mano de obra", ya que en el caso coreano fue menor de $3 \%$, mientras que en el chino menos de $1 \%$ y en el japonés, aún

${ }^{34}$ Turner, México, p. 54.

${ }^{35} \mathrm{Katz}$, Servidumbre, p. 26; Cámara, Rese$\tilde{n} a$, p. 59 
menor. Pero, si la migración asiática no fue el remedio a la escasez de la fuerza de trabajo, ¿por qué los grandes productores no presionaron para traer más trabajadores de otro lugar del mundo?, ¿acaso su argumento fue falso? Para saber si en realidad había necesidad de brazos se requiere conocer la composición general de la población en aquel estado, así como el número aproximado de trabajadores disponibles.

La población en Yucatán. Sistema

DE TRABAJO Y MANO DE OBRA

DISPONIBLE. INTERPRETACIÓN DE LA

FALTA DE MANO DE OBRA

El argumento fundamental de los productores henequeneros para llevar trabajadores asiáticos a Yucatán, como mencioné, fue la escasez de mano de obra. Pero, ¿ésta fue una causa real? Un análisis de la conformación de la población y de las características del sistema de trabajo prevalecientes en la región explican, en parte, las razones por las que los agricultores demandaban brazos del exterior.

John K. Turner y González Navarro coinciden en que a finales del porfiriato Yucatán tenía 300000 habitantes aproximadamente, de los cuales cerca de 250 formaban el grupo de hacendados, y entre 100000 y 125000 eran mayas. ${ }^{36}$ Porsu parte un autor yucateco considera que la mano de obra utilizada en la región llegaba a 111000 individuos entre mayas, chinos, coreanos

${ }^{36}$ González Navarro, Raza, p. 223; Turner, México, p. 54. y yaquis, de los cuales aproximadamente 80000 eran endeudados $y$ 30000 jornaleros libres. De los peones endeudados, un promedio de 60000 se localizaban en la zona henequenera. Ahí mismo estaban también entre 6000 y 10000 jornaleros libres. Los 20000 restantes estaban en las regiones del sur, centro y oriente del estado. ${ }^{37}$

De las cifras anteriores se desprende que cerca de una tercera parte de la población total del estado trabajaba en el cultivo de henequén. La mayoría de los trabajadores eran peones endeudados y pocos jornaleros libres. Además los hacendados utilizaron diversos métodos para adquirir mano de obra en el interior de su estado, lo cual muestra que ésta no era tan escasa como para obligarlos a llevar jornaleros extranjeros o impulsar una campaña más agresiva a fin de introducirlos.

Las transformaciones ocurridas por la concentración de la tierra y la extensión del cultivo henequenero involucraron cambios en la estructura de la población. ${ }^{38}$ La reducción de las tierras disponibles para los campesinos fue causa de que la gran mayoría pasara a depender del hacendado para su alimentación. ${ }^{39} \mathrm{Al}$ perderse el acceso a la tierra desapareció la diferencia entre el peonaje por endeudamiento y la esclavitud. ${ }^{40}$ Además, la creciente demanda de productos agrícolas, unida a la cuantiosa inversión extranjera,

37 Villanueva, Tomamos, p. 121.

38 Ibid., p. 87.

${ }^{39} \mathrm{Katz}$, Servidumbre, p. 28; Villanueva, Tomamos, p. 90.

${ }^{40} \mathrm{Katz}$, Servidumbre, p. 28. 
generó un marcado aumento del peonaje por endeudamiento con modalidades muy semejantes a la esclavitud. ${ }^{41}$

La situación se recrudeció a medida que la actividad henequenera fue creciendo y la necesidad de mano de obra se hizo más apremiante. Mayor importancia tuvo el hecho de que la legislación penal y los procedimientos otorgaron la categoría de autoridades a los mayordomos y administradores de las fincas rurales (1906). Por su parte, el Código Penal de Yucatán de 1900 consideró como vagos a los jornaleros y artesanos que sin justa causa sólo trabajaban la mitad de los días hábiles de la semana. ${ }^{42}$ Con estas leyes y decretos, así como con el apoyo total del Estado, los hacendados tuvieron las condiciones propicias para someter a los peones acasillados. ${ }^{43}$ En los últimos años del porfiriato, al desplomarse el precio del henequén y aumentar las exigencias de la International Harves. ter Corporation, la situación de estos peones empeoró progresivamente. ${ }^{44}$

En Yucatán prevaleció un sistema de coerción sobre los trabajadores. La mayoría de la fuerza de trabajo de las haciendas eran peones residentes permanentes llamados luneros. A cambio de un poco de tierra y sobre todo del agua de las fuentes de la hacienda, eran obligados a trabajar sin compensación todos los lunes, y generalmente estaban atados a la hacienda por deudas. ${ }^{45}$ Es decir, los hacendados con- taban con un grupo de trabajadores permanente.

González Navarro, Kenneth Turner y Fredrich Katz, consideran que, ante la escasez de brazos, los hacendados establecieron el sistema de servicio forzoso por deudas, mismo que era regulado a través de la "carta cuenta" que se dividía en la cuenta mayor o anual y la cuenta menor o semanal. En la primera se registraban tanto los saldos de las deudas semanales después de un año, como las deudas ocasionadas por préstamos mayores para sufragar gastos especiales (bautizos, matrimonios, defunciones, etc.). Pero la mayor parte de la deuda provenía de las mercancías recibidas en las tiendas de raya de las haciendas. 66

Los datos del proceso de acasillamiento difieren de un autor a otro, sin embargo todos ilustran el fenómeno. El profesor González Navarro considera que los sirvientes aumentaron tanto en números absolutos como en términos relativos, pasando de 20767 en 1880 a 25060 en 1883 y 26273 en 1885 . Es decir, de $8 \%$ a 9.05 y a 9.46 , respectivamente del total de la población. Según la misma fuente, en $\mathbf{1 8 8 0}$, $57 \%$ de los 260629 habitantes de Yucatán fueron censados como indígenas y el resto como vecinos (población mestiza que habitaba en los poblados). ${ }^{47}$ En general, la importancia de los sirvientes fue mayor y creciente en los partidos henequeneros, especialmente en el Acanceh. ${ }^{48}$

\footnotetext{
41 Ibid., p. 94

42 Villanueva, Tomamos, p. 94.

43 Ibid., p. 94.

${ }^{44}$ Katz, Servidumbre, p. 29.

45 Ibid., p. 19.
}

\footnotetext{
46 Villanueva, Tomamos, p. 95; González Navarro, Raza, p. 199; Turner, Méxtco, p. 60. 47 González Navarro, Raza, p. 199.

48 Ibid.
} 
Según Molina Suárez, en 1880 había 20767 peones acasillados en las haciendas y sólo 20 años después, en 1900 se rebasaba la cifra de 80000 . En 1980 Turner calculó que de los 300000 habitantes que tenía el estado, los peones acasillados eran más de $100000 .{ }^{49}$ La cifra más cercana es la proporcionada por Molina Suárez: 80000 para principios de siglo, de los cuales 60000 trabajaban en la zona henequenera. ${ }^{50}$

El proceso de acasillamiento muestra la reducción de los indígenas al trabajo en las haciendas. Asimismo presenta una gran población subordinada al trabajo en esos lugares. Los grandes agricultores tenían casi $25 \%$ de la población a su servicio, más un número considerable de indios yaquis. Esto, por otro lado, muestra que al contrario de lo argumentado por los henequeneros, había una cantidad importante de mano de obra que abastecía regularmente a las haciendas. Asimismo, no se trataba en realidad de una escasez de trabajadores, sino de población disponible. Entonces, ¿por qué en repetidas ocasiones los hacendados se quejaban de la falta de brazos? A partir de un examen de las condiciones de la región, ¿cómo interpretar esta actitud?

La inmigración de trabajadores asiáticos a Yucatán fue poca. Su representatividad como mano de obra en los campos de henequén frente al total de la fuerza de trabajo empleada también fue escasa. No llegaron a ser un grupo

49 Turner, México, p. 12; Sierra, "Yucatán", p. 12; Joseph, Revolution, p. 27.

50 Villanueva, Tomamos, p. 91. determinante para los grandes productores. Por su parte, las cifras de la población yucateca, así como el sistema de trabajo imperante, aun cuando fuera represivo y tendía a la esclavitud, muestra que no había escasez de brazos para las fincas henequeneras. Entonces cabe preguntarse: ¿cuáles fueron las razones para invertir grandes cantidades en llevar extranjeros a laborar a México y en especial a Yucatán?

Katz, González Navarro y Turner plantean la necesidad de mano de obra en las plantaciones henequeneras. Sin embargo, poco cuestionan esta hipótesis. González Navarro da un explicación al problema. Dice que en la península yucateca, por un lado se hicieron "tenaces y costosos" sacrificios por traer la inmigración extranjera, cuando en realidad, la población era grande. Sin embargo, la población nativa no era totalmente aprovechable para el desarrollo econó- mico porque los indios rebeldes eran muy numerosos. En 1893, algunos calculaban la población indígena del estado en 250 000; conceptuaban "bárbaros" a 200000 de ellos, y a los restantes 50000 los consideraban "pacíficos". Estos últimos vivían en el sur de la península, en la zona fronteriza entre Campeche y Yucatán. ${ }^{51}$ Es decir, la mayoría de la población no era dócil y por su "estado de barbarie" no eran personas que aceptaran trabajar en las fincas henequeneras, lo cual no quiere decir que muchos de ellos no hubieran sido sometidos para que laboraran. De hecho, había una división

51 González Navarro, Raza, p. 215. 


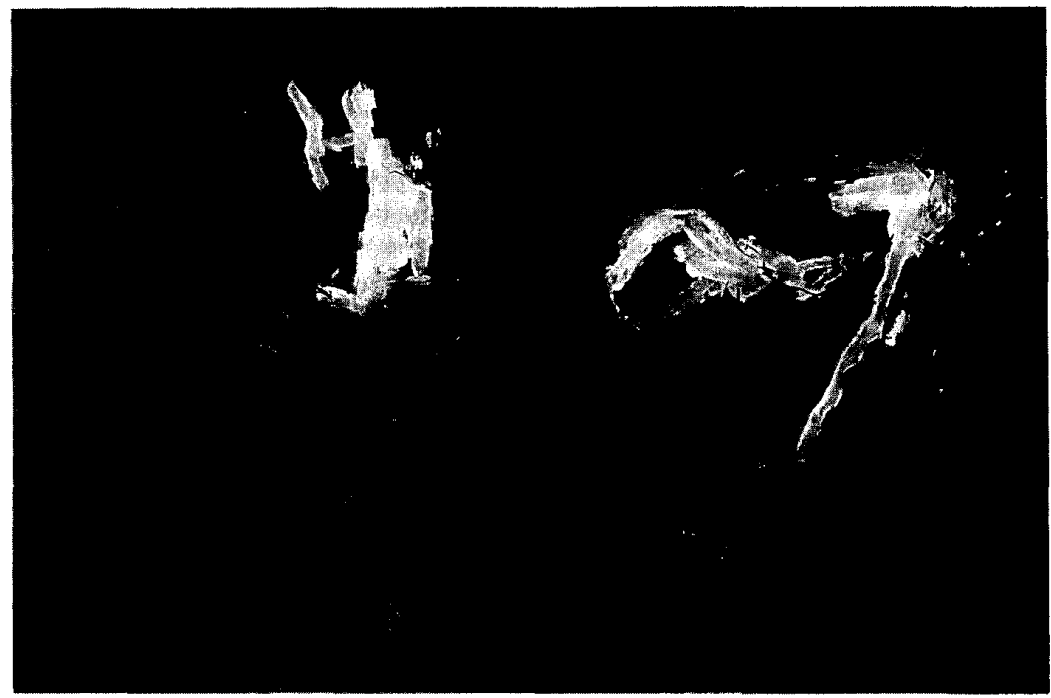

entre ellos. Estaban los que a pesar de su oposición a incorporarse totalmente, trabajaban en las plantaciones, y otro grupo más reacio a participar en el sistema laboral henequenero.

A ello se unía la concepción positivista que consideraba a la población maya, por ser indígena, sin actitudes para el desarrollo. Los indigenas estaban al margen de la cultura nacional, eran una barrera al desarrollo económico. Además no eran dóciles y en ocasiones había problemas de abasto de mano de obra por su deserción de los campos. Por esta razón, la literatura de entonces insistía en la docilidad de los chinos, actitud que consideraban un requisito fundamental.

Katz, por su parte, considera que Oaxaca y Yucatán estaban más densa- mente poblados en comparación con algunos estados del norte del país. De tal manera, que no era la falta absoluta de trabajadores la causa determinante, sino más bien la escasez de trabajadores libres en contraposición con el centro de México..$^{52} \mathrm{Al}$ respecto el autor piensa que la causa de esta escasez necesita una mayor investigación, para lo cual propone tomar en cuenta dos factores que se dieron en Yucatán: mayor número de aldeas indígenas propietarias de tierras que en la mesa central, y más caciques indígenas poderosos, quienes competían con los hacendados por la mano de obra indígena. 53

52 Katz, Servidumbre, p. 20.

53 Ibid., p. 19. 
Los hacendados yucatecos sabían que la población nativa no era escasa. Sin embargo, en su opinión, los indigenas mexicanos preferían "vivir en la abyección y morir en la miseria" a separarse de su vecindad y de su choza para trabajar en los campos henequeneros, sobre todo los mayas, los cuales tenían una tradición cultural opuesta a los intereses de los hacendados. ${ }^{54}$ Es decir, la población era abundante, pero gran parte de ella no deseaba formar parte de un sistema de trabajo extraño a su cultura. A pesar de ello, algunos pensaban que la población yucateca era pacífica y laboriosa, salvo los indios, que eran la mayoría de la población de la región. ${ }^{55}$ Debido a esto, el sistema coercitivo se hizo necesario para obtener mano de obra.

La supuesta escasez de jornaleros tiene su explicación también en el contexto del desarrollo de Yucatán a partir de la segunda mitad del siglo XIX. El momento fue de constante belicosidad entre los nuevos intereses empresariales y la población tradicional del lugar. La inestabilidad social provocada por la guerra de Castas duró alrededor de 7 años (1847-1854), aunque se prolongó hasta 1901 bajo la forma de resistencia. ${ }^{56}$ El centro de las demandas de los rebeldes lo constituían la propiedad, el uso de la tierra y el de las contribuciones. 57

En 1886, Néstor Rubio Alpuche, vicepresidente de la Sociedad Patriótica Yucateca, pidió a la Cámara de Diputados que pusiera fin a las atrevidas in-

${ }^{54}$ González Navarro, Raza, p. 175.

55 Ibid., p. 201.

56 Montalvo, "Revueltas", p. 272.

57 Ibid. cursiones de la "bárbara raza maya". Lo cierto es que de 1895 a 1901 el gobierno yucateco gastó 350416 pesos en sujetar a los mayas. En 1904, conservó destacamentos de guardia nacional en las poblaciones fronterizas de Ichmul, Chemax, Xocén, Valladolid y Peto. ${ }^{58}$ Los grupos dominantes de Yucatán fueron obligados a abandonar las tierras fértiles del sur, donde había mayor número de aldeas indígenas propietarias de tierra, yorganizar la producción agrícola restringiéndola a la zona occidental, aledaña a la capital. La guerra de Castas produjo la reorganización de la dominación blanca y su restricción alárea occidental basándose en la población sometida previamente. 59

Gastos y despliegues militares contra la población "bárbara" fueron característicos de la época. Era un hecho que estos "bárbaros" se rehusaban a ser subordinados y trabajar para ellos. Su colaboración para maximizar la producción no era posible, más aun cuando se vivía en un estado conflictivo. Sin embargo, surgieron métodos efectivos para obligarlos a laborar, los cuales se asemejaban a la esclavitud. En el transcurso de ese proceso el argumento de escasez de brazos dóciles fue válido, aun cuando no verdadero, dado el número de población sometida. La situación se puede resumir de la siguiente manera: en la mentalidad de los hacendados faltaba mano de obra porque la existente no se sometía a sus requerimientos, sin embargo existían métodos coercitivos efectivos para sojuzgarla y adquirirla.

\footnotetext{
58 González Navarro, Raza, pp. 216-217.

59 Montalvo, "Revueltas", p. 279.
} 
La supuesta falta de brazos se explica también a partir de la lucha de resistencia que desarrollaron los indígenas mayas. La forma de producir y reproducir las condiciones de existencia de los campesinos mayas libres exigía la posesión y el dominio autónomo de un territorio y una relación con la tierra mediada por múltiples elementos de carácter ideológico-cultural, entre los que destacaba la unidad integradora que otorgaba el simbolismo racial. ${ }^{60}$

La vivencia étnica de los mayas, frente a los blancos no podía darse en una región subordinada, menos aún cuando los blancos requerían a los mayas como fuerza de trabajo en sus haciendas, plantaciones e incipientes manufacturas. Para los mayas era indispensable un territorio autónomo que garantizara la continuidad de las formas de reproducción simple propias de la producción campesina, junto con la reafirmación del papel racial o étnico. Incluso la creación y articulación de mitos y rituales mágicos, respondieron al anhelo que se concretó en la idea de la nación o reino maya. ${ }^{61}$

El desarrollo en gran escala de la producción de henequén fue un factor que motivó el ingreso de los trabajadores agrícolas asiáticos en Yucatán, promovido por los productores henequeneros y otros empresarios que no contaban con fuerza de trabajo dócil. Este pretexto fue apoyado por la política gubernamental, que deseaba el ingreso de extranjeros a México para impulsar el desarrollo industrial del

${ }^{60}$ Ibid., p. 278.

61 lbid. país. El principal argumento de ambos fue la falta de brazos. Entonces se realizaron numerosos proyectos para atraer inmigrantes. Sin embargo, los asiáticos que llegaron a Yucatán fueron pocos, no tuvieron representatividad ni importancia numérica en el contexto de la fuerza de trabajo de las plantaciones henequeneras. Los que arribaron en mayor cantidad fueron los chinos, luego los coreanos y pocos japoneses.

En Yucatán la falta de brazos no fue real. La población nativa era numerosa. Por otro lado, el sistema coercitivo de trabajo, cercano a la esclavitud era eficiente y por supuesto inhumano. Además existían otros medios para obtener peones, entre los que estaban la contratación temporal, las deportaciones de yaquis, el acasillamiento, etc. De hecho los grandes henequeneros tenían a su disposición cerca de la tercera parte de la población. Entonces, la supuesta falta de fuerza de trabajo se explica por varias razones. Entre otras, por la gran cantidad de población indígena rebelde que no era aprovechable. Cerca de la mitad de la población yucateca era considerada "bárbara". Además, parte de esta gente estaba en pie de lucha, aun después de la guerra de Castas. Asimismo, habían gran número de mayas no sometidos que tenían tierras, por lo cual no dependían para su subsistencia de un hacendado y no tenían necesidad de trabajar en las plantaciones.

Finalmente la explicación principal de la falta de mano de obra es la resistencia de los mayas a servir a un sistema con el cual su cultura no se identificaba. La resistencia tenía una 
carga ideológico-cultural, relacionada con la etnia, la independencia territorial, la reafirmación racial e incluso con mitos y rituales, que se contraponía a las necesidades de fuerza de trabajo de los grandes productores yucatecos.

\section{Bibliografía}

-Cámara Zavala, Gonzalo, Reseña histórica de la industria henequenera de Yucatán, Mérida, s.e., 1936.

-Castro Aguilar, Pedro, Colonizar es poblar, Publicaciones de la Federación de Organizaciones Populares de Yucatán, Mérida, 1948.

-Gómez Izquierdo, José Jorge, El movimiento antichino en México (1871-1934). Problemas del racismo y del nacionalismo durante la revolución mexicana, tesis de licenciatura en Sociología, Facultad de Ciencias Políticas-unam, México, 1988.

-González, Blanca, "El porfiriato henequenero en Yucatán", en Yucatán peonaje yliberación, FONAPAS/INAH, México, 1978.

-González Navarro, Moisés, La colonización en México 1877-1910, Talleres de Impresión de Estampillas y Valores, México, 1960.

, Los extranjeros en México y los mexicanos en el extranjero 1821-1970, El Colegio de México, México, 1994. , Raza y tierra: la guerra de Castas y el henequén, Centro de Estudios Históricos-El Colegio de México, México, 1979.

-Joseph, G. M., Revolution from without; Yucatan, Mexico, and the United States 1880-1924, Cambridge University Press, Cambridge, 1982.

-Katz, Friedrich (comp.), Revuelta, rebelión y revolución; la lucha rural en México del siglo XVI al siglo $\mathrm{XX}$, Era, México, 1990, (Col. Problemas de México).
La servidumbre agraria en México en la época porfiriana, Ediciones Era, México, 1987 (Col. Problemas de México).

-Molina Font, Gustavo, La tragedia de Yucatán, Jus/Revista de Derecho y Ciencias Sociales, México, 1941.

-Montalvo Ortega, Enrique, "Revueltas y movilizaciones campesinas en Yucatán; indios, peones y campesinos de la guerra de Castas a la revolución", en Friedrich Katz (comp.), Revuelta.

-Monsely, Edward H. y Edward D. Terry, Yucatán a world apart, The University of Alabama Press, Alabama.

-Patterson, Wayne, Korean immigration to the Yucatan at the turn of the century; the diplomatic consequences, Sait Norbert College, De Pere, Wisconsin. Ponencia presentada en la $24^{\mathrm{a}}$ convención anual de la Asociación de Estudios Internacionales, 1983.

-Pong Hyon, Paek, The Koreans in Mexico 1905-1911, tesis de maestría, The University of Texas at Austin, 1968.

-Puig Llano, Juan Mauricio, La matanzade chinos en Torreón en 1911: historia de un incidente internacional, tesis de licenciatura, Facultad de Filosofía y LetrasUNAM, México, 1986.

-Romero Castillo, Alfredo, "Los coreanos en México", Eslabones. Revista semestral de estudios regionales, núm. 9, junio, 1995, México.

"Haciendas henequeneras de Yucatán. Los primeros coreanos", México Indígena, enero-febrero, núms. 16-17, 1991, México.

-Sierra V., José Luis, "Yucatán 18501910 ", en Yucatán peonaje y liberación, FONAPAS/INAH, Mérida, 1981.

-Turner, John Kenneth, México bárbaro, Ariel, México, 1989.

-Villanueva MuKul, Eric, Así tomamos las tierras; henequén y haciendas en Yucatán durante el porfiriato, Malonado/ INAH, México, 1984 (Col. Raíces). 